\title{
Medication Use Patterns and Predictors of Nonpersistence and Nonadherence with Oral 5-Aminosalicylic Acid Therapy in Patients with Ulcerative Colitis
}

\author{
Linnette Yen, MS, MA; Joanne Wu, MS; Paul Hodgkins, PhD, MSc; \\ Russell D. Cohen, MD; and Michael B. Nichol, PhD
}

\begin{abstract}
BACKGROUND: 5-aminosalicylic acid (5-ASA) is the recommended firstline treatment for active mild-to-moderate ulcerative colitis (UC) and for maintenance of UC remission. However, persistence and adherence to prescribed 5-ASAs are often suboptimal.
\end{abstract}

OBJECTIVE: To evaluate 5-ASA medication use patterns and assess risk factors associated with nonpersistence and nonadherence to oral 5-ASA medications in UC patients.

METHODS: IMS LifeLink Health Plan claims data (January 2007 to June 2011) were analyzed. We identified adult patients (18 years or older) with at least 1 diagnosis of UC (ICD-9-CM code $=556 . x$ [ulcerative colitis]) and at least 1 pharmacy claim for an oral 5-ASA (balsalazide disodium, sulfasalazine, mesalamine delayed-release, and Multi-Matrix System mesalamine) during the study period. Patients were required to have continuous eligibility on both health and pharmacy plans for 6 months pre- and 12 months postinitial pharmacy claim (index date). Medication use patterns (discontinuation, time to discontinuation [days], switch, and nonadherence) in the 12 months following the index date were evaluated. Nonpersistence or discontinuation with the index medication was defined as a treatment gap $\geq 60$ days. Switch was identified as patients changing to another 5-ASA product after discontinuing the index medication. Nonadherence to index medication was determined by medication possession ratio (MPR) $<0.8$ for the index medication. Nonadherence to any 5-ASA treatment was determined by a proportion of days covered (PDC) $<0.8$ for any 5-ASA. A Cox model was used to assess the relative hazards associated with discontinuation. Multiple logistic regression models were used to assess risk factors associated with nonadherence to either the index or any 5-ASA medications.

RESULTS: A total of 5,664 patients met selection criteria. The median time to discontinuation of index drug differed significantly across index medications (range, 98.5 days [sulfasalazine] to 177.5 days [Multi-Matrix System mesalamine], $P<0.0001)$. Patients on Multi-Matrix System mesalamine were less likely to discontinue $(63.3 \%$ vs. $\geq 68.6 \%, P=0.001)$ and more likely to adhere to their medication (MPR $\geq 0.8 ; 23.1 \%$ vs. $\leq 17.4 \%$, $P<0.0001$ ) than patients on other medications. Patients on mesalamine delayed-release (13.8\%) or Multi-Matrix System mesalamine (14.3\%) had lower switch rates than the patients on balsalazide $(17.2 \%)$ or sulfasalazine $(17.8 \%), P=0.01$. Significant predictors of nonpersistence included index medication versus Multi-Matrix System mesalamine (balsalazide disodium: $\mathrm{HR}=1.21,95 \% \mathrm{Cl}=1.07-1.36$; mesalamine delayed-release: $\mathrm{HR}=1.21, \mathrm{Cl}=1.11-1.32$; sulfasalazine: $\mathrm{HR}=1.40, \mathrm{Cl}=1.25-1.57$ ), female gender $(\mathrm{HR}=1.16, \mathrm{Cl}=1.09-1.23)$, never receiving specialist care $(\mathrm{HR}=1.14$, $\mathrm{Cl}=1.07-1.21$ ), preferred provider organization (PP0) versus health maintenance organization $(\mathrm{HR}=1.14, \mathrm{Cl}=1.04-1.24)$, and Medicare fee for service or self-insured health plan versus commercial plan $(H R=1.29$, $\mathrm{Cl}=1.10-1.52)$. Significant variables associated with nonadherence with 5-ASA treatment $(\mathrm{PDC}<0.8)$ included not switching medication $(\mathrm{OR}=1.90$, $\mathrm{Cl}=1.58-2.29)$, age $<65(\mathrm{OR}=1.90, \mathrm{Cl}=1.56-2.31)$, index medication as compared with Multi-Matrix System mesalamine (balsalazide disodium: $\mathrm{OR}=1.43, \mathrm{Cl}=1.10-1.85$; mesalamine delayed-release: $\mathrm{OR}=1.41, \mathrm{Cl}=1.19$ 1.68; sulfasalazine: $\mathrm{OR}=1.66, \mathrm{Cl}=1.30,2.12)$, female gender $(\mathrm{OR}=1.33$, $\mathrm{Cl}=1.17-1.52$ ), residing in different regions as compared with the Midwest region (the South $[\mathrm{OR}=1.40, \mathrm{Cl}=1.20-1.64]$ and Northeast $[\mathrm{OR}=1.29$, $\mathrm{Cl}=1.05-1.58])$, no use of rectal forms during the post-index period $(0 \mathrm{R}=1.28, \mathrm{Cl}=1.08-1.50)$, no use of immunosuppressive/biologic agents during the post-index period $(0 \mathrm{R}=1.70, \mathrm{Cl}=1.35-2.14)$, never receiving specialist care $(\mathrm{OR}=1.25, \mathrm{Cl}=1.08-1.44)$, and Medicaid/Medicare versus commercial plan $(\mathrm{OR}=1.48, \mathrm{Cl}=1.03-2.13)$.

CONCLUSIONS: Patients on once-daily dosed Multi-Matrix System mesalamine had the lowest risk of discontinuation and the highest adherence rate. Multiple factors were associated with either nonpersistence or nonadherence, including multiple-daily dosed index medication, younger age, female gender, residing in the South region, PPO plan, noncommercial payer, not using immunosuppressive/biologic agents, not using rectal 5-ASA, and never receiving specialist care.

J Manag Care Pharm. 2012;18(9):701-12

Copyright $\odot 2012$, Academy of Managed Care Pharmacy. All rights reserved.

\section{What is already known about this subject}

- According to clinical practice guidelines from 2 organizations (the British Society of Gastroenterology and American College of Gastroenterology Practice Parameters Committee), 5-aminosalicylic acid (5-ASA) is a recommended first-line treatment for patients with mild-to-moderate ulcerative colitis (UC). However, adherence to medication is suboptimal. Literature reports show that $40 \%$ to $72 \%$ of patients are nonadherent to their treatment regimen.

- Most studies of adherence in UC patients have been based on either clinical trials or observational studies with small samples. Only 2 published studies have used administrative claims data to investigate 5-ASA medication persistence. All of them had significant limitations related to study design and adherence measurement.

- Multiple factors including age, gender, newly diagnosed patient status, disease duration, copayment amount, rectal 5-ASA and glucocorticoid use, and drug type and multiple daily dosed regimens have been associated with nonadherence to 5-ASA medications 


\section{Medication Use Patterns and Predictors of Nonpersistence and Nonadherence with Oral 5-Aminosalicylic Acid Therapy in Patients with Ulcerative Colitis}

\section{What this study adds}

- The present study investigated various medication use patterns including discontinuation, restart, switch, and adherence using "real-world" pharmacy and medical claims data.

- Oral 5-ASA use patterns varied among patients initiated on different 5-ASA medications. The patients on Multi-Matrix System mesalamine had the lowest discontinuation/nonpersistency rate (63.3\% vs. $\geq 68.6 \%$ ), longest median time remaining on index drug (177.5 days vs. $\leq 148$ days), lowest hazard to discontinue (HR $=1.21$ [balsalazide, mesalamine delayed-release], and 1.4 [sulfasalazine]) as compared with patients on other 5-ASA medications.

- Significant nonadherence with oral 5-ASA treatment in UC patients was shown with rates ranging from $74.2 \%$ to $82.0 \%$ for those initiated on Multi-Matrix System mesalamine and sulfasalazine, respectively.

- Several factors (multiple daily dosed index medication, younger age, female gender, residing in the South, preferred provider plan, noncommercial payer, not using immunosuppressive/biologic agents, not using rectal 5-ASA, and never receiving specialist care) were associated with nonpersistence or nonadherence with 5-ASAs.

- Analyses based on descriptive medication use patterns and different multivariable models confirmed that multiple daily dosed index medication (including balsalazide, mesalamine delayedrelease, or sulfasalazine) was one of the significant factors associated with 5-ASA nonpersistence or nonadherence as compared with once-daily Multi-Matrix System mesalamine. Therefore, Multi-Matrix System mesalamine with once-daily dosing formulation may improve adherence in patients with UC.

$\mathrm{U}$ lcerative colitis (UC) is a chronic inflammatory bowel disease (IBD) characterized by chronic or recurring immune-mediated injury to the large intestine (i.e., colon and rectum). The inflammation in UC is typically limited to the mucosal lining, starting in the rectum and extending proximally to affect part or all of the colon. The inflammation is typically circumferential and continuous, with "skip areas" of normal mucosa. The estimated prevalence of UC ranges from 37.5 to 248.6 per 100,000 persons in North America. ${ }^{1}$ UC is a costly disease and poses a significant economic burden, in which the estimated cost is in the range of $\$ 8.1-\$ 14.9$ billion in the United States. ${ }^{2}$

The nature of UC typically requires lifelong pharmacological therapy to induce and maintain remission. First-line treatment with 5-aminosalicylic acid (5-ASA) is recommended for mild-to-moderate disease. ${ }^{3-5}$ However, clinical studies have reported medication nonadherence rates from $40 \%$ to $72 \% .6,7$ Current systematic reviews reveal that nonadherence with 5-ASA has substantial clinical implications, including a greater risk of relapse of UC, impaired quality of life, increased health care costs, and the potential for increased lifetime risk of developing colorectal cancer.-13

Multiple factors associated with nonadherence with UC medications have been identified. ${ }^{6,7,13-15}$ These factors include age, gender, newly diagnosed patient status, disease duration, copayment costs, rectal 5-ASA and glucocorticoid use, and drug type and dosing regimens. Some of these studies have reported that adherence is related to dosing regimens, while other studies have not found a correlation between these concepts. For example, a few studies in UC patients showed that daily dose, regimen, and formulation do not significantly impact adherence. ${ }^{7,13}$ In addition, adherence in UC patients appears to be independent of medication formulation. ${ }^{13}$ However, the study conducted by Loftus (2006) from a survey of 1,595 patients with UC showed the most common reasons for nonadherence were "too many pills," "dosing required too many times each day," "medication too inconvenient," and "forgetting to take medication."16

Shale and Riley (2003) also identified that a 3-times-a-day regimen was associated with nonadherence. ${ }^{17}$ Recent studies have demonstrated that once-daily mesalamine is effective for induction or maintenance of remission in quiescent patients. ${ }^{18-20}$ Moreover, a recent patient survey reported significantly higher self-reported compliance and acceptability in the once-daily group than in the twice-daily group. ${ }^{18}$ These studies supported the use of once-daily treatment for improving medication adherence in UC patients.

Most of the medication adherence studies in UC patients were either clinical trials or observational studies with small samples. The findings and conclusions from these types of studies may not be easily generalized to real-world clinical practice, since the study patients are monitored more closely than in conventional practice. Few studies have investigated 5-ASA utilization patterns and persistency using administrative claims data that may approximate real-world clinical practice. ${ }^{15,21}$ However, the few published studies using claims data analysis have significant flaws in identifying appropriate UC patients (e.g., without using diagnosis codes to confirm UC patient $\mathrm{s}^{21}$ ) and measurement of persistency (e.g., persistency was measured by refill rate at the third and the twelfth month. ${ }^{15}$ ). Moreover, these studies only investigated medication persistency but did not assess medication adherence. Identifying oral 5-ASA medication use patterns and risk factors associated with nonpersistence and nonadherence may help determine formulary decisions, as well as design and intervention programs to improve medication adherence and patients health outcomes. The objective of this study was to evaluate oral 5-ASA medication use patterns and assess risk factors associated with nonpersistence and nonadherence for both index and subsequent oral 5-ASA medications in UC patients. 


\section{Medication Use Patterns and Predictors of Nonpersistence and Nonadherence with Oral 5-Aminosalicylic Acid Therapy in Patients with Ulcerative Colitis}

\section{Methods}

\section{Data Source and Patients Selection}

The IMS LifeLink Health Plan Claims Database includes longitudinal, integrated, and patient-level medical and pharmaceutical claims from across the United States. The data include records of more than 70 million patients from over 75 health plans and incorporates the data for medical services and prescription drug information across the entire continuum of care. ${ }^{22}$ The records in the database are generally representative of the national commercially insured population in terms of age and gender. ${ }^{22}$ Multi-Matrix System mesalamine was approved by the U.S. Food and Drug administration (FDA) on January 16, 2007, while other 5-ASA medications reported in the current study were approved by the FDA before this date; therefore, data from January 2007 to July 2011 were analyzed.

Patients were selected if they met the following criteria: (a) aged 18 years or older; (b) presence of at least 1 initial oral 5-ASA pharmacy claim (index date) based on the National Drug Codes (NDCs) during July 2007 to July 2010; (c) at least 1 UC diagnosis (International Classification of Diseases, Ninth Revision, Clinical Modification [ICD-9-CM] code $=556 . x$ [ulcerative colitis]) from the medical claims for the first 4 diagnosis codes for the 6 months prior to and the 12 months after the index date; (d) continuously enrolled in both health and pharmacy plans for the 6 months prior to and the 12 months after the index date; and (e) no pharmacy claim for any 5-ASA, corticosteroids, or immunosuppressive/biologic agents in the 6 months prior to the index date. Patients were excluded if they had a diagnosis in the medical claims data for the first 4 diagnosis codes for Crohn's disease (ICD-9-CM code $=555 . \mathrm{x}$ [regional enteritis]), or irritable bowel syndrome (ICD-9-CM code $=564.1$ [irritable bowel syndrome, irritable colon, spastic colon, functional disorder of the colon that is generally psychosomatic]) during the 18-month study period.

5-ASA medications based on NDC codes used to identify patients included the products that are currently available in the United States: Multi-Matrix System mesalamine (Lialda); mesalamine delayed-release (Asacol); mesalamine controlledrelease (Pentasa, Apriso); balsalazide (Colazal, generic balsalazide disodium); olsalazine (Dipentum); and sulfasalazine (Azulfidine, Azulfidine EN, Sulfazine, Sulfazine EC, and generic sulfasalazine). The initial 5-ASA was defined as index medication. The cohorts with small sample sizes (multiple index drugs, in which patients had pharmacy claims for more than 1 5-ASA on the index date $[\mathrm{N}=18]$, index olsalazine $[\mathrm{N}=43]$, and index mesalamine controlled-release (Apriso $[N=68]$, Pentasa $[N=171]$ ) were excluded from the analysis (Figure 1).

\section{Medication Use Patterns}

In order to provide a consistent study sample and to require that all patients had the same follow-up period for a valid comparison, medication use patterns (discontinuation, restart of treatment after discontinuation, switch, and nonadherence) in the 12 months post-index date were evaluated. Patients with discontinuation or nonpersistency to index medication experienced a gap of at least 60 days for the index medication or at least 60 days without medication before the last day of the study period for that patient. A gap of 60 days (twice the duration of a monthly prescription) was consistent with a published 5-ASA persistent study. ${ }^{21}$ Although patients may need to switch medications due to side effects, lack of treatment efficacy, or other reasons, investigating discontinuation or nonpersistency to index medication provided important information on how patients behaved on their index medications and how long they stayed on the index medication. Restart was defined as the patients who refilled the index medication following discontinuation. Switch was defined as the patients who changed to a second 5-ASA drug after discontinuing the index medication. Two types of switches were defined. The first, "switch without gap" categorized patients that overlapped or initiated the new 5-ASA medication within 60 days of the last index drug filled. The second type, "switch with gap," categorized patients that initiated the new 5-ASA medication at least 60 days after the discontinuation of the index 5-ASA. Therefore, patients were further stratified to 4 categories after discontinuing the index medication: (a) no further treatment (neither switch to other 5-ASA nor restart of the index 5-ASA medication); (b) switch to another 5-ASA medication, including switch with and without a gap; (c) restart the index medication; and (d) switch and restart, in which the patients may switch to another 5-ASA drug, then discontinue, and then restart the index 5-ASA drug, or they could restart the index 5-ASA drug during the rest of follow-up period, then switch to a different 5-ASA drug. The duration from initiation to the first discontinuation of the index medication represented persistency. Time to discontinuation, restart, and switch were evaluated.

Medication adherence was summarized using medication possession ratio (MPR) or proportion of days covered (PDC), in which we followed the International Society for Pharmacoeconomics and Outcomes Research (ISPOR) Good Outcomes Research Practices guidelines for the medication adherence methods. ${ }^{23,24}$ In order to understand patients' medication taken behavior on their index medications and subsequent oral 5-ASA medications, we assessed adherence to index medication and adherence to any 5-ASA medication. The MPR was calculated as the total number of days of index medication supplied divided by the number of days in the specified time interval (360 days). The PDC was calculated as the number of days with any oral 5-ASA drug on hand divided by the number of days in the specified time interval (360 days). A uniform period of 1 year (360 days) was used in our calculation to ensure equal and accurate long-term adherence behavior profiles. Overlapping pharmacy claims (e.g., an early refill) for the 


\section{Medication Use Patterns and Predictors of Nonpersistence and Nonadherence with Oral 5-Aminosalicylic Acid Therapy in Patients with Ulcerative Colitis}

\section{FIGURE 1 Sample Selection Flowchart}

$\geq 1$ oral 5 -ASA prescription fill during July 2007 to July 2010 $\mathrm{N}=109,961$

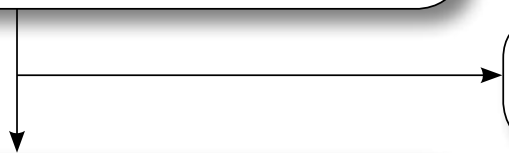

With $\geq 1$ diagnosis of ulcerative colitis 6 months prior to and 12 months after index date

$$
\mathrm{N}=44,055
$$



Without a diagnosis of ulcerative colitis 6 months prior to and 12 months after index date $\mathrm{N}=65,906$ 


\section{Medication Use Patterns and Predictors of Nonpersistence and Nonadherence with Oral 5-Aminosalicylic Acid Therapy in Patients with Ulcerative Colitis}

index medication were assessed for MPR based on the assumption that the prior supply was taken fully before the new supply was initiated, so the start date for a refill was delayed until the prior supply had been exhausted. However, if switching therapy occurred, or a new prescription for a different medication was filled before a previous prescription was expected to expire, it was assumed that the leftover supply from the previous medication was discarded to begin the new drug. Because there may have been more than a total 360 days of prescription fills within one year, MPR was commonly truncated at 1.0. Nonadherence to index medication was determined by MPR $<0.8$, while nonadherence to any 5-ASA medications was defined by $\mathrm{PDC}<0.8 .^{23}$

\section{Independent Variables}

Sociodemographic risk indicators included age, gender, and region (Northeast, South, Midwest, and West). Health insurance information included payer type (commercial plan, selfinsured, Medicare fee for service [FFS], Medicaid, Medicare Risk, and unknown) and plan product type (consumerdirected health care [CDHC], indemnity plan [IP], point of service [POS], health maintenance organization [HMO], preferred provider organization [PPO], and unknown).

Existing comorbid conditions were assessed by Elixhauser comorbidity scores measured during the 6 months prior to the index date. ${ }^{25}$ This measure includes 31 conditions and was calculated as the sum of number of comorbidities present in the medical claims data.

Four clinical variables (specialist visits, currently used corticosteroids, immunosuppressive/biologics agents, and the rectal form of 5-ASA) were measured during the 12 months post-index date. A specialist visit was determined by a medical claim associated with a specialty of colorectal surgery or gastroenterology. Corticosteroid use was defined as having at least one pharmacy claim for the drug class of glucocorticosteroids based on the NDC codes. Immunosuppressive use was defined as having at least one pharmacy claim of either azathioprine, 6-mercaptopurine, cyclosporine, or tacrolimus. Biologic agent use was defined as having at least one pharmacy claim of either infliximab, adalimumab, or certolizumab based on the NDC codes. Patients who used immunosuppressive or biologic agents were identified and were treated as a covariate variable. Patients with the rectally applied 5-ASAs (Rowasa enemas or suppositories; Canasa suppositories) were identified from the pharmacy claims associated with the NDC codes.

\section{Statistical Analyses}

Descriptive statistics summarize patient demographic and clinical characteristics, as well as medication use patterns across index medications. Differences among index medication cohorts were tested using chi-square tests for categorical variables, and one-way analyses of variance (ANOVAs) for continu- ous variables. Due to skewed data distribution for the variables of time to events for medication use patterns, median and range were also calculated. Nonparametric Wilcoxon tests were performed to test the event differences among index medications. One-way ANOVA Kruskal-Wallis test statistics were reported. Analysis of covariance was used to compare MPR and PDC among index medications. Covariate adjusted mean MPR or PDC were estimated from the predicted population marginal mean. If significant differences were found, Tukey multiple comparison tests for adjusting the overall significance level were used to identify significant pairwise differences. A Cox proportional hazards model was used to assess relative hazards associated with discontinuation of index drugs. Multiple logistic regressions with stepwise selection were used to assess risk factors associated with nonadherence.

A survival curve describing the crude discontinuous behavior of oral index 5-ASA treatment was generated using the Kaplan-Meier method. Patients who remained on their index medication until the end of the 360 days follow-up period were considered as censored data, and the length of remaining therapy during follow-up was assigned as their survival time. All analyses were conducted using SAS software (Version 9.2, SAS Institute, Inc., Cary, NC).

\section{Results}

\section{Patient Characteristics}

A total of 5,644 patients were included in the analysis (Figure 1). Table 1 describes patient demographic and clinical characteristics stratified by index medication. Mean age was 48.3 \pm 15.4 years. Patients on Multi-Matrix System mesalamine were more likely to have a PPO plan (76.6\%) than those on other index medication (range: $71.9 \%$ [sulfasalazine] to $73.0 \%$ [balsalazide], $P<0.0001$ ). Patients from the South were more likely to have a pharmacy claim for balsalazide (43.4\%) than for the other 5-ASA drugs (range: 28.5\% [sulfasalazine] to 39.7\% [Multi-Matrix System mesalamine], $P<0.0001$ ). Mean Elixhauser comorbidity scores were significantly different across index medication samples $(P<0.0001)$. Overall, $34.7 \%$ of patients had at least one pharmacy claim for corticosteroids, $6.8 \%$ for immunosuppressive/biologic agents and $18.3 \%$ for a rectal 5-ASA during the 12 months post-index date. There were a greater number of specialist visits in patients on Multi-Matrix System mesalamine (2.0 \pm 2.3$)$, balsalazide $(1.9 \pm 2.2)$, or mesalamine delayed-release $(1.9 \pm 2.4)$ than those on sulfasalazine $(1.4 \pm 2.0, P<0.0001)$.

\section{Medication Use Patterns}

Sixty-nine percent of patients discontinued their index medication during the 12 months post-index date (Table 2). Approximately $57 \%$ of discontinued patients did not have further 5-ASA treatment (neither restart the index drug nor switch to another drug), while $23.4 \%$ restarted the index drug; 


\section{Medication Use Patterns and Predictors of Nonpersistence and Nonadherence with Oral 5-Aminosalicylic Acid Therapy in Patients with Ulcerative Colitis}

\section{TABLE 1 Patient Characteristics Stratified by Index Drug}

\begin{tabular}{|c|c|c|c|c|c|c|c|c|c|c|c|}
\hline \multirow{2}{*}{$\frac{\text { Variable }}{\text { Number of patients (\%) }}$} & \multicolumn{2}{|c|}{ Total } & \multicolumn{2}{|c|}{ MMS } & \multicolumn{2}{|c|}{ Balsalazide } & \multicolumn{2}{|c|}{ MDR } & \multicolumn{2}{|c|}{ Sulfasalazine } & \multirow{2}{*}{$\frac{P \text { Value }^{\mathrm{a}}}{\text { NA }}$} \\
\hline & 5,664 & $(100.0)$ & 922 & $(16.3)$ & 551 & $(9.7)$ & 3,395 & $(59.9)$ & 796 & $(14.1)$ & \\
\hline Age in years, mean (SD) & 48.3 & $(15.4)$ & 45.3 & $(14.5)$ & 46.2 & $(14.7)$ & 48.5 & $(15.5)$ & 52.2 & $(15.4)$ & $<0.0001$ \\
\hline Age category (\%) & & & & & & & & & & & $<0.0001$ \\
\hline$<65$ Years & 4,921 & $(86.9)$ & 851 & $(92.3)$ & 489 & $(88.7)$ & 2,938 & $(86.5)$ & 643 & $(80.8)$ & \\
\hline$\geq 65$ Years & 743 & $(13.1)$ & 71 & $(7.7)$ & 62 & $(11.3)$ & 457 & $(13.5)$ & 153 & $(19.2)$ & \\
\hline Gender (\%) & & & & & & & & & & & $<0.0001$ \\
\hline Female & 2,989 & $(52.8)$ & 472 & $(51.2)$ & 281 & $(51.0)$ & 1,873 & $(55.2)$ & 363 & $(45.6)$ & \\
\hline Male & 2,675 & $(47.2)$ & 450 & $(48.8)$ & 270 & $(49.0)$ & 1,522 & $(44.8)$ & 433 & $(54.4)$ & \\
\hline Index year (\%) & & & & & & & & & & & $<0.0001$ \\
\hline 2007 & 1,553 & $(27.4)$ & 139 & $(15.1)$ & 200 & $(36.3)$ & 971 & $(28.6)$ & 243 & $(30.5)$ & \\
\hline 2008 & 2,243 & $(39.6)$ & 396 & $(43.0)$ & 211 & $(38.3)$ & 1,337 & $(39.4)$ & 299 & $(37.6)$ & \\
\hline 2009 & 1,422 & $(25.1)$ & 303 & $(32.9)$ & 95 & $(17.2)$ & 823 & $(24.2)$ & 201 & $(25.3)$ & \\
\hline 2010 & 446 & $(7.9)$ & 84 & $(9.1)$ & 45 & $(8.2)$ & 264 & $(7.8)$ & 53 & $(6.7)$ & \\
\hline Payer type (\%) & & & & & & & & & & & $<0.0001$ \\
\hline Commercial plan & 4,379 & $(77.3)$ & 722 & $(78.3)$ & 451 & $(81.9)$ & 2,610 & $(76.9)$ & 596 & $(74.9)$ & \\
\hline Medicare FFS/self-insured/unknown & 1,023 & $(18.1)$ & 181 & $(19.6)$ & 83 & $(15.1)$ & 632 & $(18.6)$ & 127 & $(16.0)$ & \\
\hline SCHIP/Medicaid/Medicare risk & 262 & $(4.6)$ & 19 & $(2.1)$ & 17 & $(3.1)$ & 153 & $(4.5)$ & 73 & $(9.2)$ & \\
\hline Plan product type (\%) & & & & & & & & & & & $<0.0001$ \\
\hline CDHC/IP/POS & 773 & $(13.6)$ & 93 & $(10.1)$ & 74 & $(13.4)$ & 503 & $(14.8)$ & 103 & $(12.9)$ & \\
\hline $\mathrm{HMO}$ & 854 & $(15.1)$ & 100 & $(10.8)$ & 72 & $(13.1)$ & 569 & $(16.8)$ & 113 & $(14.2)$ & \\
\hline $\mathrm{PPO}$ & 3,948 & $(69.7)$ & 706 & $(76.6)$ & 402 & $(73.0)$ & 2,268 & $(66.8)$ & 572 & $(71.9)$ & \\
\hline Unknown & 89 & $(1.6)$ & 23 & $(2.5)$ & 3 & $(0.5)$ & 55 & (1.6) & 8 & $(1.0)$ & \\
\hline Region (\%) & & & & & & & & & & & $<0.0001$ \\
\hline Midwest & 2,358 & $(41.6)$ & 306 & $(33.2)$ & 194 & $(35.2)$ & 1,529 & $(45.0)$ & 329 & $(41.3)$ & \\
\hline Northeast & 791 & $(14.0)$ & 174 & $(18.9)$ & 81 & $(14.7)$ & 474 & $(14.0)$ & 62 & $(7.8)$ & \\
\hline South & 1,823 & $(32.2)$ & 366 & $(39.7)$ & 239 & $(43.4)$ & 991 & $(29.2)$ & 227 & $(28.5)$ & \\
\hline West & 692 & $(12.2)$ & 76 & $(8.2)$ & 37 & $(6.7)$ & 401 & $(11.8)$ & 178 & $(22.4)$ & \\
\hline Elixhauser comorbidity, mean (SD) & 0.9 & $(1.4)$ & 0.8 & $(1.2)$ & 0.7 & $(1.2)$ & 1.0 & (1.4) & 1.0 & (1.4) & $<0.0001$ \\
\hline Used corticosteroids (\%) & 1,967 & $(34.7)$ & 331 & $(35.9)$ & 189 & $(34.3)$ & 1,191 & $(35.1)$ & 256 & $(32.2)$ & 0.38 \\
\hline Used immunosuppressive/biologic agents (\%) & 386 & $(6.8)$ & 70 & $(7.6)$ & 56 & $(10.2)$ & 224 & $(6.6)$ & 36 & $(4.5)$ & 0.001 \\
\hline Used rectal form of 5-ASA (\%) & 1,039 & $(18.3)$ & 221 & $(24.0)$ & 132 & $(24.0)$ & 601 & $(17.7)$ & 85 & $(10.7)$ & $<0.0001$ \\
\hline Number of specialist visits, mean (SD) & 1.8 & $(2.3)$ & 2.0 & $(2.3)$ & 1.9 & $(2.2)$ & 1.9 & $(2.4)$ & 1.4 & $(2.0)$ & $<0.0001$ \\
\hline $\begin{array}{l}\text { Note: Data were presented as mean (SD) for conti } \\
\text { a } P \text { values were calculated from one-way ANOVA } f \\
5-A S A=5 \text {-aminosalicylic acid; ANOVA = analysis } \\
I P=\text { indemnity plan; MMS = Multi-Matrix System } \\
\text { organization; } S D=\text { standard deviation. }\end{array}$ & $\begin{array}{l}\text { ous varia } \\
\text { continuor }\end{array}$ & $\begin{array}{l}\text { bles, num } \\
\text { us variabl } \\
\text { CDHC }\end{array}$ & $\begin{array}{l}\text { (columi } \\
\text { and chi- }\end{array}$ & $\begin{array}{l}\text { percenta } \\
\text { square tes }\end{array}$ & $\begin{array}{l}\text { for cate } \\
\text { for cate }\end{array}$ & $\begin{array}{l}\text { orical vo } \\
\text { orical va }\end{array}$ & $\begin{array}{l}\text { ables. } \\
\text { ibles. }\end{array}$ & 1010 & . & 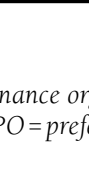 & ation; \\
\hline
\end{tabular}

$18 \%$ switched to another 5-ASA drug, and approximately 2\% of the patients had both restart and switch behaviors. The overall median time to discontinuation was 137 days (ranging from 2 to 300 days). The median times to discontinuation were significantly different among index medications, ranging from 98.5 days for the patients on sulfasalazine to 177.5 days for those on Multi-Matrix System mesalamine $(P<0.0001)$. The probability that patients remained on the 5-ASA therapy substantially decreased after the 30th day (Figure 2), and further decreased on the 90th day, especially for those on sulfasalazine, mesalamine delayed-release, and balsalazide. The substantial decrease in persistence on the 30th and 90th days may relate to an initial fill with 30 or 90 days supply. The patients on sulfasalazine (23\%) had higher proportion with 90 days supply than those on other index drugs, e.g., 10\% for Multi-Matrix System mesalamine. Patients on Multi-Matrix System mesalamine were significantly less likely to discontinue the index medication than those on other medications $(P<0.0001$, Figure 2$)$.

The median time to restart index medication after discontinuation was 98 days (ranging from 59 to 331 days) and was similar among the index drug groups $(P=0.31)$. Within the whole sample, $14.8 \%$ of patients switched medications. Patients were less likely to switch if the index medication was mesalamine delayed-release ( $\mathrm{N}=468,13.8 \%)$ or Multi-Matrix System mesalamine ( $\mathrm{N}=132,14.3 \%)$ than if it were balsalazide $(\mathrm{N}=95,17.2 \%)$, or sulfasalazine $(\mathrm{N}=142,17.8 \% ; \mathrm{P}=0.01)$. Of the 837 patients who switched, 92\% switched with at least a 60-day gap; median time to switch was similar among index 


\section{Medication Use Patterns and Predictors of Nonpersistence and Nonadherence with Oral 5-Aminosalicylic Acid Therapy in Patients with Ulcerative Colitis}

\section{TABLE 2 Medication Use Patterns Stratified by Index Medication}

\begin{tabular}{|c|c|c|c|c|c|c|}
\hline \multirow{2}{*}{$\begin{array}{l}\text { Variable } \\
\mathrm{N}(\%) \\
\end{array}$} & Total & MMS & Balsalazide & MDR & Sulfasalazine & \multirow{2}{*}{$\frac{P \text { Value }^{\mathrm{a}}}{\text { NA }}$} \\
\hline & $5,664 \quad(100.0)$ & $922 \quad(16.3)$ & $(9.7)$ & $3,395 \quad(59.9)$ & $796 \quad(14.1)$ & \\
\hline Discontinuation of index medication (\%) & $3,891 \quad(68.7)$ & (63.3) & $378 \quad(68.6)$ & $2,356 \quad(69.4)$ & (72.0) & 0.001 \\
\hline Medication used after discontinuation (\%) ${ }^{\mathrm{b}}$ & & & & & & 0.04 \\
\hline No further 5-ASA treatment & $2,212 \quad(56.9)$ & $341 \quad(58.4)$ & $(51.3)$ & $(57.8)$ & $(55.2)$ & \\
\hline Restart index drug & $909 \quad(23.4)$ & $123 \quad(21.1)$ & $95 \quad(25.1)$ & $568 \quad(24.1)$ & $123 \quad(21.5)$ & \\
\hline Switch to another 5-ASA & $699 \quad(18.0)$ & $107 \quad(18.3)$ & $80 \quad(21.2)$ & $(16.6)$ & $(20.9)$ & \\
\hline Restart and switch & $(1.8)$ & $(2.2)$ & $(2.4)$ & $(1.5)$ & $(2.4)$ & \\
\hline \multicolumn{7}{|l|}{ Time to discontinuation of index drug (days) ${ }^{b}$} \\
\hline Mean (SD) & $177.5 \quad(135.9)$ & $193.7(138.2)$ & $179.8 \quad(135.1)$ & $175.7 \quad(135.5)$ & $164.9 \quad(133.9)$ & 0.0001 \\
\hline Median & 137.0 & 177.5 & 148.0 & 135.0 & 98.5 & $<0.0001$ \\
\hline Range & 2 to 300 & 2 to 300 & 2 to 300 & 2 to 300 & 4 to 300 & \\
\hline \multicolumn{7}{|l|}{$\begin{array}{l}\text { Time to restart index drug after discontinuation } \\
\text { (days) }{ }^{\mathrm{b}}\end{array}$} \\
\hline Mean (SD) & $119.8 \quad(61.5)$ & $113.1 \quad(57.4)$ & $121.8 \quad(62.8)$ & $120.1 \quad(62.9)$ & $123.3 \quad(58.5)$ & 0.53 \\
\hline Median & 98.0 & 94.0 & 98.5 & 98.0 & 104.0 & 0.31 \\
\hline Range & 59 to 331 & 59 to 299 & 59 to 313 & 59 to 331 & 59 to 324 & \\
\hline Switch index drug (\%) & $837 \quad(14.8)$ & $(14.3)$ & $95 \quad(17.2)$ & $468 \quad(13.8)$ & $(17.8)$ & 0.01 \\
\hline Without gap (\%) & $(8.0)$ & $(9.1)$ & $(6.3)$ & $(8.8)$ & $(5.6)$ & \\
\hline With gap (\%) & $770 \quad(92.0)$ & $120 \quad(90.9)$ & $(93.7)$ & $(91.2)$ & $(94.4)$ & \\
\hline Time to switch index drugc & & & & & & 0.55 \\
\hline Mean (SD) & $136.3 \quad(106.2)$ & $139.4 \quad(109.1)$ & $152.8 \quad(116.5)$ & $134.3 \quad(101.5)$ & $128.6 \quad(110.9)$ & \\
\hline Median & 107.0 & 103.0 & 117.0 & 114.0 & 90.5 & 0.29 \\
\hline Range & 2 to 360 & 2 to 357 & 2 to 352 & 2 to 358 & 5 to 360 & \\
\hline $\begin{array}{l}\text { aP values were calculated from one-way ANOVA } \\
\text { sponding row for median) for the continuous var } \\
\text { bData only included patients who discontinued in } \\
\text { 'Data only included patients who switched index } \\
5 \text {-ASA =5-aminosalicylic acid; ANOVA=analys } \\
\text { SD=standard deviation. }\end{array}$ & $\begin{array}{l}\text { nted in the corresp } \\
\text { ad chi-square tests } \\
\text { dication. }\end{array}$ & $\begin{array}{l}\text { ding row for mean } \\
\text { the categorical val }\end{array}$ & $\begin{array}{l}\text { D]) and nonparam } \\
\text { ables. }\end{array}$ & ric Kruskal-Wallis & sts (presented in th & corre- \\
\hline
\end{tabular}

medications - 107 days (ranging from 2 to 360 days; $P=0.29$ ).

The analysis of covariance reported in Table 3 shows that covariate-adjusted oral 5-ASA medication adherence was significantly greater in patients on Multi-Matrix System mesalamine (MPR/PDC: $0.51 \pm 0.02 / 0.58 \pm 0.02$ ) than those on balsalazide $(0.47 \pm 0.02 / 0.54 \pm 0.02)$ or mesalamine delayed-release $(0.46 \pm 0.01 / 0.54 \pm 0.01)$ or sulfasalazine $(0.42 \pm 0.02 / 0.52 \pm 0.02)$, for MPR $(P<0.01)$ and PDC $(P<0.02)$, respectively. Nonadherence rates for each index drug ranged from a low of $76.9 \%$ for those on Multi-Matrix System mesalamine to $85.2 \%$ for those on sulfasalazine and were significantly different among index medications $(P<0.0001)$. Overall nonadherence rate for any 5 -ASA medication was $79 \%$, ranging from $74.2 \%$ for patients on Multi-Matrix System mesalamne to $82 \%$ for those on sulfasalazine.

\section{Risk Factors Associated with Discontinuation of Index Medication}

Analysis from the multivariable Cox model indicated that factors associated with discontinuation of index medication included younger patients (hazard ratio $[\mathrm{HR}]=0.991$, 95\% confidence interval $[\mathrm{CI}]=0.989-0.993)$, patients on index balsalazide $(\mathrm{HR}=1.21, \mathrm{CI}=1.07-1.36)$, mesalamine delayedrelease $(\mathrm{HR}=1.21, \mathrm{CI}=1.11-1.32)$, or sulfasalazine $(\mathrm{HR}=1.40$, $\mathrm{CI}=1.25-1.57$ ), as compared with those on Multi-Matrix System mesalamine, female gender $(\mathrm{HR}=1.16, \mathrm{CI}=1.09-1.23)$, never receiving specialist care $(\mathrm{HR}=1.14, \mathrm{CI}=1.07-1.21)$, and a greater number of comorbidities $(\mathrm{HR}=1.05, \mathrm{CI}=1.02-1.07)$. Patients with a PPO plan $(\mathrm{HR}=1.14, \mathrm{CI}=1.04-1.24)$ versus $\mathrm{HMO}$, or with a plan payer for Medicare FFS or self-insured ( $\mathrm{HR}=1.29, \mathrm{CI}=1.10-1.52)$ versus commercial plan were more likely to discontinue the index medication (Table 4).

\section{Predictors of Nonadherence with Index or Any 5-ASA Medication}

Table 5 presents the results for stepwise multivariable logistic regression models. Significant predictors for index drug nonadherence $(\mathrm{MPR}<0.8)$ included the following: age younger than 65 years (odds ratio $[\mathrm{OR}]=1.84, \mathrm{CI}=1.53-2.23$ ); index medication versus Multi-Matrix System mesalamine (balsalazide: $\mathrm{OR}=1.49, \mathrm{CI}=1.13-1.95$, mesalamine delayed-release: $\mathrm{OR}=1.60, \mathrm{CI}=1.33-1.92$, sulfasalazine: $\mathrm{OR}=1.89, \mathrm{CI}=1.47-2.45$ ); 


\section{Medication Use Patterns and Predictors of Nonpersistence and Nonadherence with Oral 5-Aminosalicylic Acid Therapy in Patients with Ulcerative Colitis}

\section{TABLE 3 Medication Adherence Measure Stratified by Index Drug}

\begin{tabular}{|c|c|c|c|c|c|c|c|c|c|c|}
\hline \multirow{2}{*}{$\begin{array}{l}\text { Variable } \\
\text { Number of patients (\%) }\end{array}$} & Total & \multicolumn{2}{|c|}{ MMS } & \multicolumn{2}{|c|}{ Balsalazide } & \multicolumn{2}{|c|}{ MDR } & \multicolumn{2}{|c|}{ Sulfasalazine } & \multirow{2}{*}{$\frac{P \text { Value }^{\mathbf{a}}}{\text { NA }}$} \\
\hline & $5,664(100.0)$ & 922 & $(16.3)$ & 551 & $(9.7)$ & 3,395 & $(59.9)$ & 796 & $(14.1)$ & \\
\hline \multicolumn{11}{|l|}{ Adherence to index drug } \\
\hline Unadjusted MPR, mean (SD) & $0.43 \quad(0.31)$ & 0.47 & $(0.32)^{*}$ & 0.43 & $(0.30)^{\dagger}$ & 0.43 & $(0.31)^{\dagger}$ & 0.39 & $(0.30)^{\ddagger}$ & $<0.0001$ \\
\hline Adjusted MPR, mean (SE) & NA & 0.51 & $(0.02)^{*}$ & 0.47 & $(0.02)^{\dagger}$ & 0.46 & $(0.01)^{\dagger}$ & 0.42 & $(0.02)^{\ddagger}$ & $<0.01$ \\
\hline Adherence of index drug (\%) & & & & & & & & & & $<0.0001$ \\
\hline MPR: $<0.50$ & $3,241 \quad(57.2)$ & 475 & $(51.5)$ & 315 & $(57.2)$ & 1,949 & $(57.4)$ & 502 & $(63.1)$ & \\
\hline MPR: $0.50-0.79$ & $1,429 \quad(25.2)$ & 234 & $(25.4)$ & 140 & $(25.4)$ & 879 & (25.9) & 176 & $(22.1)$ & \\
\hline MPR: $\geq 0.80$ & $994 \quad(17.6)$ & 213 & $(23.1)$ & 96 & $(17.4)$ & 567 & $(16.7)$ & 118 & $(14.8)$ & \\
\hline \multicolumn{11}{|l|}{ Adherence to any 5-ASA drug } \\
\hline Unadjusted PDC, mean (SD) & $0.48 \quad(0.31)$ & 0.51 & $(0.31)^{*}$ & 0.48 & $(0.30)^{*, \dagger}$ & 0.48 & $(0.31)^{\dagger}$ & 0.45 & $(0.30)^{\dagger}$ & $<0.0001$ \\
\hline Adjusted PDC, mean (SE) & NA & 0.58 & $(0.02)^{*}$ & 0.54 & $(0.02)^{\dagger, \ddagger}$ & 0.54 & $(0.01)^{\dagger}$ & 0.52 & $(0.02)^{\ddagger}$ & $<0.02$ \\
\hline Adherence of any 5-ASA drug (\%) & & & & & & & & & & 0.002 \\
\hline PDC: $<0.50$ & $2,906 \quad(51.3)$ & 434 & $(47.1)$ & 281 & $(51.0)$ & 1,748 & $(51.5)$ & 443 & $(55.6)$ & \\
\hline PDC: $0.50-0.79$ & $1,568 \quad(27.7)$ & 250 & $(27.1)$ & 157 & $(28.5)$ & 951 & $(28.0)$ & 210 & $(26.4)$ & \\
\hline PDC: $\geq 0.8$ & $1,190 \quad(21.0)$ & 238 & $(25.8)$ & 113 & $(20.5)$ & 696 & $(20.5)$ & 143 & $(18.0)$ & \\
\hline \multicolumn{11}{|c|}{ 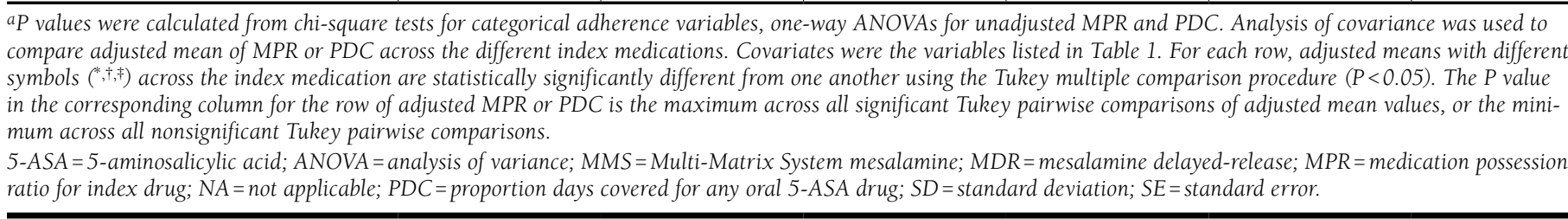 } \\
\hline
\end{tabular}

\section{TABLE 4 Risk Factors Associated with Discontinuation of Index Drug from Cox Model}

\begin{tabular}{l|c|c|c|c}
\hline Variable & HR & \multicolumn{2}{|c|}{$95 \%$ CI } & $P$ Value \\
\hline Age & 0.991 & 0.989 & 0.993 & $<0.0001$ \\
\hline Index drug & & & & $<0.0001$ \\
\hline Multi-Matrix System mesalamine & 1.00 & & & \\
\hline Balsalazide & 1.21 & 1.07 & 1.36 & 0.002 \\
\hline Mesalamine delayed-release & 1.21 & 1.11 & 1.32 & $<0.0001$ \\
\hline Sulfasalazine & 1.40 & 1.25 & 1.57 & $<0.0001$ \\
\hline Female gender & 1.16 & 1.09 & 1.23 & $<0.0001$ \\
\hline Never receiving specialist care & 1.14 & 1.07 & 1.21 & $<0.0001$ \\
\hline Elixhauser comorbidities & 1.05 & 1.02 & 1.07 & 0.0002 \\
\hline Plan product type & & & & 0.01 \\
\hline HMO & 1.0 & & & \\
\hline CDHC/IP/POS & 0.99 & 0.88 & 1.13 & 0.95 \\
\hline PPO & 1.14 & 1.04 & 1.24 & 0.005 \\
\hline Plan payer type & & & & 0.008 \\
\hline Commercial plan & 1.0 & & & \\
\hline Medicaid/Medicare risk & 0.99 & 0.92 & 1.09 & 0.98 \\
\hline Medicare FFS/self-insured & 1.29 & 1.10 & 1.52 & 0.002 \\
\hline Note: Cox proporionat
\end{tabular}

Note: Cox proportional hazards model with stepwise selection was performed to assess the factors associated with discontinuing index drug. The variables presented in Table 1 with $P$ values $<0.2$ from the univariate analyses were included in the model. Only the significant variables in the order of the steps entered to the model were presented in the table (variables with $P$ values $>0.05$ are not reported). $C I=$ confidence interval,$C D H C=$ consumer -directed health care; FFS = fee for service; $H M O=$ health maintenance organization; $H R=$ hazard ratio; $I P=$ indemnity plan; $P O S=$ point of service; $P P O=$ preferred provider organization . female gender $(\mathrm{OR}=1.34, \mathrm{CI}=1.16-1.54)$; residing in the different geographic regions as compared with the Midwest (West $[\mathrm{OR}=1.38, \mathrm{CI}=1.10-1.75]$, South $[\mathrm{OR}=1.46, \mathrm{CI}=1.23-1.72]$, and Northeast $[\mathrm{OR}=1.28, \mathrm{CI}=1.03-1.58]$ ); no use of immunosuppressive/biologic agents during 12 months post-index date $(\mathrm{OR}=1.39, \mathrm{CI}=1.08-1.79)$, and never receiving specialist care $(\mathrm{OR}=1.20, \mathrm{CI}=1.04-1.39)$.

Significant predictors for nonadherence with any 5-ASA drug (PDC < 0.8 ) were similar with those for nonadherence with the index drug (Table 5). In addition, no history of switching the index drug was the most important factor associated with nonadherence with any 5-ASA drug (OR $=1.90, \mathrm{CI}=1.58$ 2.29). Other factors included no use of the rectal form of 5-ASA $(\mathrm{OR}=1.28, \mathrm{CI}=1.08-1.50)$ in the post-index study period. Those with a Medicaid/Medicare risk payer were significantly associated with nonadherence with any 5-ASA medication $(\mathrm{OR}=1.48, \mathrm{CI}=1.03-2.13)$.

\section{Discussion}

The medication nonadherence rate in our study (79\%) was higher than those previously reported from epidemiological or clinical studies based on nonstandardized self-report questionnaires, nonstandardized patient/parent interviews, pill counts, or pharmacy records, which ranged from $40 \%$ to $72 \%$. ${ }^{6,7}$ This finding confirms the problem of medication nonadherence in UC patients in the United States. Oral 5-ASA medication use 


\section{Medication Use Patterns and Predictors of Nonpersistence and Nonadherence with Oral 5-Aminosalicylic Acid Therapy in Patients with Ulcerative Colitis}

\section{TABLE 5 Logistic Regression Models Predicting Nonadherence with Index or Any Oral 5-ASA Medication}

\begin{tabular}{|c|c|c|c|c|c|c|c|c|c|c|}
\hline \multirow{3}{*}{$\begin{array}{l}\text { Variable } \\
\text { No switch from index drug }\end{array}$} & \multicolumn{5}{|c|}{ Nonadherence with Index Drug (MPR $<0.8)$} & \multicolumn{5}{|c|}{ Nonadherence with Any 5-ASA Drug (PDC <0.8) } \\
\hline & \multirow{2}{*}{$\begin{array}{l}\text { OR } \\
\text { NA }\end{array}$} & \multicolumn{2}{|c|}{$95 \% \mathrm{CI}$} & \multirow[t]{2}{*}{$P$ Value } & \multirow[t]{2}{*}{$\begin{array}{c}\text { Step } \\
\text { Order }\end{array}$} & \multirow{2}{*}{$\begin{array}{l}\text { OR } \\
1.90\end{array}$} & \multicolumn{2}{|c|}{$95 \%$ CI } & \multirow{2}{*}{$\begin{array}{l}P \text { Value } \\
<0.0001\end{array}$} & \multirow{2}{*}{$\begin{array}{c}\begin{array}{c}\text { Step } \\
\text { Order }^{\mathrm{a}}\end{array} \\
1\end{array}$} \\
\hline & & & & & & & 1.58 & 2.29 & & \\
\hline Age $<65$ years vs. $\geq 65$ years & 1.84 & 1.53 & 2.23 & $<0.0001$ & 1 & 1.90 & 1.56 & 2.31 & $<0.0001$ & 2 \\
\hline Index drug & & & & $<0.0001$ & 2 & & & & 0.0001 & 5 \\
\hline Multi-Matrix System mesalamine & 1.0 & & & & & 1.0 & & & & \\
\hline Balsalazide & 1.49 & 1.13 & 1.95 & 0.004 & & 1.43 & 1.10 & 1.85 & 0.007 & \\
\hline Mesalamine delayed-release & 1.60 & 1.33 & 1.92 & $<0.0001$ & & 1.41 & 1.19 & 1.68 & 0.0001 & \\
\hline Sulfasalazine & 1.89 & 1.47 & 2.45 & $<0.0001$ & & 1.66 & 1.30 & 2.12 & $<0.0001$ & \\
\hline Female gender vs. male & 1.34 & 1.16 & 1.54 & $<0.0001$ & 3 & 1.33 & 1.17 & 1.52 & $<0.0001$ & 4 \\
\hline Region & & & & 0.0003 & 4 & & & & 0.0003 & 6 \\
\hline Midwest & 1.0 & & & & & 1.0 & & & & \\
\hline West & 1.38 & 1.10 & 1.75 & 0.007 & & 1.35 & 1.08 & 1.69 & 0.008 & \\
\hline South & 1.46 & 1.23 & 1.72 & $<0.0001$ & & 1.40 & 1.20 & 1.64 & $<0.0001$ & \\
\hline Northeast & 1.28 & 1.03 & 1.58 & 0.02 & & 1.29 & 1.05 & 1.58 & 0.02 & \\
\hline Rectal form of 5-ASA not used & & & & & & 1.28 & 1.08 & 1.50 & 0.004 & 7 \\
\hline Immunosuppressive/biologic agents not used & 1.39 & 1.08 & 1.79 & 0.01 & 5 & 1.70 & 1.35 & 2.14 & $<0.0001$ & 3 \\
\hline Never receiving specialist care & 1.20 & 1.04 & 1.39 & 0.02 & 6 & 1.25 & 1.08 & 1.44 & 0.002 & 8 \\
\hline Plan payer type & & & & & & & & & & 9 \\
\hline Commercial plan & & & & & & 1.0 & & & & \\
\hline Medicaid/Medicare risk & & & & & & 1.48 & 1.03 & 2.13 & 0.03 & \\
\hline Medicare FFS/self-insured & & & & & & 0.89 & 0.75 & 1.06 & 0.18 & \\
\hline C statistic & \multicolumn{5}{|c|}{$C=0.61$} & \multicolumn{5}{|c|}{$C=0.63$} \\
\hline Hosmer and Lemeshow Goodness of Fit Test & \multicolumn{5}{|c|}{ Chi-square $=13.21, P=0.10$} & \multicolumn{5}{|c|}{ Chi-square $=4.04, P=0.85$} \\
\hline \multicolumn{11}{|c|}{$\begin{array}{l}\text { Note: Logistic regression models with stepwise selection were performed to assess the factors associated with nonadherence with index drug }(M P R<0.8) \text { and nonadherence } \\
\text { with any oral } 5 \text {-ASA medications }(P D C<0.8) \text {. Variables entered in the models for the analysis were those presented in Table } 1 \text {. Only the statistically significant variables } \\
\text { in the final step were presented in Table } 5 \text { (variables with } P \text { values }>0.05 \text { are not reported). } \\
\text { aStep order is the order of the significant variables entered into the logistic regression model, which indicates the importance of the variables. } \\
5 \text {-ASA =5-aminosalicylic acid; CI = confidence interval, FFS =fee for service; MPR = medication possession ratio; NA=not applicable; OR=odd ratio; PDC=proportion of } \\
\text { days covered. }\end{array}$} \\
\hline
\end{tabular}

patterns varied among patients initiated on different 5-ASA medications. Patients on Multi-Matrix System mesalamine were at the lowest risk to discontinue the index medication, as they had the lowest discontinuation/nonpersistency rate, the longest median days remaining on their index drug, the lowest probability to discontinue from the survival analysis, and were less likely to discontinue in a Cox proportional hazards model as compared with the patients on any of the other 5-ASA index drugs. Patients on Multi-Matrix System mesalamine were also less likely to switch drugs as compared with those on balsalazide or sulfasalazine. Patients on Multi-Matrix System mesalamine had the lowest oral index 5-ASA nonadherence rate $(76.9 \%)$ among the index drug samples. Based on the survival curves, the probabilities of remaining on therapy (persistency to the index drug) at 360 days was $24 \%$ for patients on Multi-Matrix System mesalamine, 19\% for mesalamine delayed-release, $18 \%$ for balsalazide, and $16 \%$ for sulfasalazine $(P<0.0001$, Figure 2). Our results indicated that patients on Multi-Matrix System mesalamine had a significantly higher probability to be persistent to their medication than those on other 5-ASA medications.

A recent study conducted by Kane et al. (2011)21 analyzed a large U.S. pharmacy data file to examine persistency with oral 5-ASA therapy in UC patients. They found that patients receiving once-daily Multi-Matrix System mesalamine had a significantly higher persistence rate after 1 year of treatment than those receiving other oral 5-ASA therapies. Our findings on discontinuation/nonpersistency to the index medication are consistent with these results, although our study used different patient selection criteria and different treatment pattern definitions.

The present study also addresses an important issue in the literature: the conflicting reports on the relationship between formulation and nonadherence. ${ }^{7,13,16-18,21,26,27}$ Although a few studies reported that daily dose regimen and formulation do not significantly impact adherence,, 132 current studies using patient surveys revealed that frequent dosing and pill burden were important factors for nonadherence. ${ }^{16,26}$ Similarly, 2 


\section{Medication Use Patterns and Predictors of Nonpersistence and Nonadherence \\ with Oral 5-Aminosalicylic Acid Therapy in Patients with Ulcerative Colitis}

\section{FIGURE 2 Time to Discontinuation by Index Medications in a 360-Day Study Period}

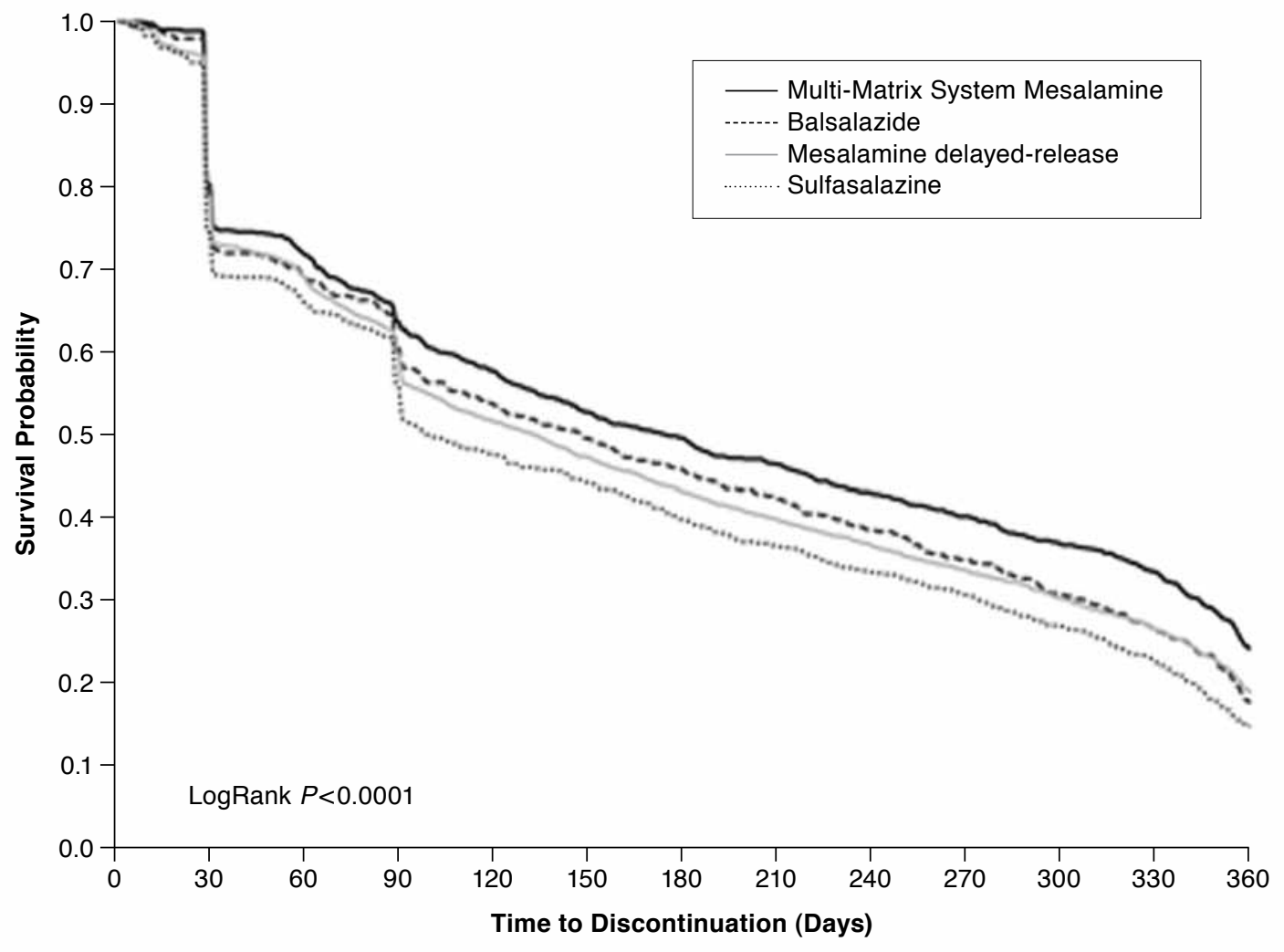

clinical observational studies have indicated that multipledaily dosing is associated with medication nonadherence in UC patients. ${ }^{8,17}$ The results from our study indicated that patients on once-daily dosing Multi-Matrix System mesalamine had the lowest nonadherence as measured by either the mean MPR or by the proportion of patients with an MPR lower than 0.8 . Moreover, the mean MPRs were significantly different across the index drug samples, even with demographic and clinical characteristics adjustments. When medication adherence measurement accounted for drug switching, adherence to any 5-ASA drug as measured by PDC was greater than MPR; patients on once-daily Multi-Matrix System mesalamine had the highest PDC. Moreover, the results from the logistic regression analyses indicated that the choice of index medication was a significant factor associated with nonadherence. Patients on balsalazide, mesalamine delayed-release, and sulfasalazine were more likely to be nonadherent as compared with those on Multi-Matrix System mesalamine. These results further demonstrated that the once-daily dosing 5-ASAs may have a significant impact on medication adherence.

From the logistic regression analyses, our study showed that the factors associated with nonadherence with index 5-ASA or with any 5-ASA medication were similar. In addition, the results revealed that a history of switching was one of the most important factors associated with patient adherence with the oral 5-ASA medication therapy. Since the patients on mesalamine delayed-release or Multi-Matrix System mesalamine were less likely to switch, they were adherent with their index drug to remain on the therapy, while those on balsalazide or sulfasalazine switched from the index 5-ASA to nonindex 5-ASA more frequently.

A recent systematic review concluded that demographic, clinical, and treatment variables were not consistently associated with nonadherence to oral medication in IBD. ${ }^{27}$ Specifically, reports of the impact of age and gender on nonadherence were inconsistent. ${ }^{26-32}$ We found that being younger than 65 years and being female were independently associated with nonadherence. Although age and gender are not mutable factors, these factors may have different impacts on responses to drug therapy. Therefore, personalized therapy should be considered when treating patients with UC.

Clinical variables such as disease duration, clinical activity, and extent/location have been reported to be significantly associated with nonadherence. ${ }^{26}$ As one of the limitations using 


\section{Medication Use Patterns and Predictors of Nonpersistence and Nonadherence with Oral 5-Aminosalicylic Acid Therapy in Patients with Ulcerative Colitis}

claims data for adherence research, we do not have detailed clinical information. However, we found that patients who did not use immunosuppressive/biologic agents, or who did not use the rectal form of 5-ASA, were significantly associated with nonadherence to oral 5-ASA treatment. Immunosuppressive/ biologic agents are usually given to patients who do not respond to 5-ASAs or corticosteroids or who are dependent on corticosteroids. ${ }^{3-5}$ The rectal form of 5-ASA is effective in inducing and maintaining remission in patients with UC limited to the distal colon and rectum. Therefore, these variables served as a proxy measurement of disease severity or location. Patients with less severe conditions tended to be nonadherent. Also, patients taking the rectal form tended to be more adherent with oral 5-ASA medication.

Findings related to residential region may indicate that physician practices varied by region. In addition, we found that patients with a public insurance payer (Medicaid or Medicare risk) were significantly associated with nonadherence with any oral 5-ASA as compared with a commercial plan. Insurance coverage is known to increase access to care and to improve health outcomes. ${ }^{33,34}$ Appropriate public insurance redesign for UC patients may adequately provide for health care that UC patients need to improve medication adherence.

\section{Limitations}

Claims data analyses have some common limitations. We were not able to determine whether and to what extent patients actually used the prescribed medication because information in the data refers to filled prescriptions. Additionally, the reasons for the medication use patterns, such as discontinuation and switch cannot be determined. Administrative claims data lack socioeconomic (e.g., income and educational levels) and clinical information (e.g., disease severity, activity, and duration) and may also contain coding errors. Despite these limitations, results from previous studies support the use of pharmacy claims data to measure adherence $e^{35,36}$ and have been widely applied in many chronic diseases. ${ }^{37-39}$

\section{Conclusion}

Oral 5-ASA medication use patterns varied among index drugs. Once-daily Multi-Matrix System mesalamine had the lowest risk of discontinuation and highest adherence rate. Multiple factors were significantly associated with nonpersistence or nonadherence with 5-ASA, including multiple-daily dosed index medication, younger age, female gender, residing in the South region, PPO plan, noncommercial payer, not using immunosuppressive/biologic agents, not using rectal form of 5-ASA, and never receiving specialist care. This research provides clinicians with insights into patient variables associated with 5-ASA medication nonpersistence/nonadherence and may help make informed decisions on future programs designed to target specified risk factors to improve medication persistency and adherence in patients with UC.

\section{Authors}

LINNETTE YEN, MS, MA, is Director, and PAUL HODGKINS, $\mathrm{PhD}, \mathrm{MSc}$, is Senior Director, Global Health Economics and Outcomes Research, Shire Development LLC, Wayne, Pennsylvania. JOANNE WU, MS, is Research Associate, School of Pharmacy and Leonard D. Schaeffer Center for Health Policy and Economics, and MICHAEL B. NICHOL, PhD, is Professor, School of Pharmacy, Sol Price School of Public Policy, and Leonard D. Schaeffer Center for Health Policy and Economics, University of Southern California, Los Angeles, California. RUSSELL D. COHEN, MD, is Professor of Medicine, Pritzker School of Medicine, University of Chicago Medical Center, Chicago, Illinois.

AUTHOR CORRESPONDENCE: Linnette Yen, MS, MA, Global Health Economics and Outcomes Research, Shire Development LLC, 725 Chesterbrook Blvd., Wayne, PA 19087. Tel.: 484-358-6220; E-mail: lyen@shire.com.

\section{DISCLOSURES}

Sponsored by Shire Development LLC, Linnette Yen and Paul Hodgkins are employees of Shire Development LLC; Joanne Wu and Michael Nichol were financially supported by an unrestricted research agreement between Shire Development LLC and the University of Southern California. Russell Cohen reports consulting work for Shire, Salix, and Warner Chilcott and has received honoraria for lectures from Shire.

Concept and design were developed by Yen, Wu, Nichol, and Hodgkins. Data were collected by $\mathrm{Wu}$ and Yen, and interpreted by $\mathrm{Wu}$, Yen, Nichol Hodgkins, and Cohen. The manuscript was written by Wu with the assistance of Nichol and Yen. Revisions were made by all coauthors.

\section{REFERENCES}

1. Molodecky NA, Soon IS, Rabi DM, et al. Increasing incidence and prevalence of the inflammatory bowel diseases with time, based on systematic review. Gastroenterology. 2012;142(1):46-54. Available at: http://download.journals.elsevierhealth.com/pdfs/journals/0016-5085/ PIIS0016508511013783.pdf. Accessed November 11, 2012.

2. Cohen RD, Yu AP, Wu EQ, Xie J, Mulani PM, Chao J. Systematic review: the costs of ulcerative colitis in Western countries. Aliment Pharmacol Ther. 2010;31(7):693-707.

3. Carter MJ, Lobo AJ, Travis SP. Guidelines for the management of inflammatory bowel disease in adults. Gut. 2004;53(Suppl 5):V1-V16. Available at: http://www.ncbi.nlm.nih.gov/pmc/articles/PMC1867788/pdf/v053p000vl. pdf. Accessed November 11, 2012

4. Kornbluth A, Sachar DB; Practice Parameters Committee of the American College of Gastroenterology. Ulcerative colitis practice guidelines in adults (update): American College of Gastroenterology, Practice Parameters Committee. Am J Gastroenterol. 2004;99(7):1371-85.

5. Mowat C, Cole A, Windsor A, et al. Guidelines for the management of inflammatory bowel disease in adults. Gut. 2011;60(5):571-607.

6. Kane SV, Robinson A. Review article: understanding adherence to medication in ulcerative colitis-innovative thinking and evolving concepts. Aliment Pharmacol Ther. 2010;32(9):1051-58.

7. Lakatos PL. Prevalence, predictors, and clinical consequences of medical adherence in IBD: how to improve it? World J Gastroenterol. 2009;15(34):4234-39. Available at: http://www.ncbi.nlm.nih.gov/pmc/articles/PMC2744179/pdf/WJG-15-4234.pdf. Accessed November 11, 2012. 


\section{Medication Use Patterns and Predictors of Nonpersistence and Nonadherence with Oral 5-Aminosalicylic Acid Therapy in Patients with Ulcerative Colitis}

8. Kane S, Huo D, Aikens J, Hanauer S. Medication nonadherence and the outcomes of patients with quiescent ulcerative colitis. Am J Med. 2003;114(1):39-43

9. Kane SV. Systematic review: adherence issues in the treatment of ulcerative colitis. Aliment Pharmacol Ther. 2006;23(5):577-85. Available at: http://onlinelibrary.wiley.com/doi/10.1111/j.1365-2036.2006.02809.x/pdf. Accessed November 11, 2012.

10. Bernick SJ, Kane S. Insight into the widespread problem of nonadherence to therapy in ulcerative colitis patients. Expert Rev Clin Immunol. 2010;6(4):677-82.

11. Olmstead J. Oral 5-aminosalicylic acid therapy for mild-to-moderate ulcerative colitis. J Am Acad Nurse Pract. 2010;22(11):586-92.

12. Higgins PD, Rubin DT, Kaulback K, Schoenfield PS, Kane SV. Systematic review: impact of nonadherence to 5-aminosalicylic acid products on the frequency and cost of ulcerative colitis flares. Aliment Pharmacol Ther. 2009;29(3):247-57. Available at: http://onlinelibrary.wiley.com/doi/10.1111/ j.1365-2036.2008.03865.x/pdf. Accessed November 11, 2012

13. Kane SV, Brixner D, Rubin DT, Sewitch MJ. The challenge of compliance and persistence: focus on ulcerative colitis. J Manag Care Pharm. 2008;14 (1 Suppl A):S2-S12. Available at: http://www.amcp.org/data/jmcp/ JMCPSuppA_Jan08.pdf.

14. Hawthorne AB, Rubin G, Ghosh S. Review article: medication nonadherence in ulcerative colitis-strategies to improve adherence with mesalazine and other maintenance therapies. Aliment Pharmacol Ther. 2008;27(12):1157-66. Available at: http://onlinelibrary.wiley.com/doi/10.1111/j.1365-

2036.2008.03698.x/pdf. Accessed November 11, 2012.

15. Kane SV, Accortt NA, Magowan S, Brixner D. Predictors of persistence with 5-aminosalicylic acid therapy for ulcerative colitis. Aliment Pharmacol Ther. 2009;29(8):855-62. Available at: http://onlinelibrary.wiley.com/ doi/10.1111/j.1365-2036.2009.03941.x/pdf. Accessed November 11, 2012

16. Loftus EV Jr. A practical perspective on ulcerative colitis: patients' needs from aminosalicylate therapies. Inflamm Bowel Dis. 2006;12(12):

1107-13. Available at: http://onlinelibrary.wiley.com/doi/10.1097/01. mib.0000235831.01682.8d/pdf. Accessed November 11, 2012.

17. Shale MJ, Riley SA. Studies of compliance with delayed-release mesalazine therapy in patients with inflammatory bowel disease. Aliment Pharmacol Ther. 2003;18(2):191-98. Available at: http://onlinelibrary.wiley.com/ doi/10.1046/j.1365-2036.2003.01648.x/pdf. Accessed November 11, 2012

18. Dignass AU, Bokemeyer B, Adamek $\mathrm{H}$, et al. Mesalamine once daily is more effective than twice daily in patients with quiescent ulcerative colitis. Clin Gastroenterol Hepatol. 2009;7(7):762-69.

19. Kruis W, Kiudelis G, Rácz I, et al. Once daily versus three times daily mesalazine granules in active ulcerative colitis: a double-blind, double-dummy, randomised, non-inferiority trial. Gut. 2009;58(2):233-40. Available at: http://www.ncbi.nlm.nih.gov/pmc/articles/PMC3269751/pdf/GUT-58-020233.pdf. Accessed November 11, 2012.

20. Sandborn WJ, Kamm MA, Lichtenstein GR, Lyne A, Butler T, Joseph RE. MMX Multi Matrix System mesalazine for the induction of remission in patients with mild-to-moderate ulcerative colitis: a combined analysis of two randomized, double-blind, placebo-controlled trials. Aliment Pharmacol Ther. 2007;26(2):205-15. Available at: http://onlinelibrary.wiley.com/doi/10.1111/ j.1365-2036.2007.03361.x/pdf. Accessed November 11, 2012

21. Kane SV, Sumner M, Solomon D, Jenkins M. Twelve-month persistency with oral 5-aminosalicylic acid therapy for ulcerative colitis: results from a large pharmacy prescriptions database. Dig Dis Sci. 2011;56(12):3463-70.

22. IMS LifeLink Health Plan Claims Database. PharMetrics, Inc., a unit of IMS Health. Watertown, WA. Copyright 2010. All Rights Reserved.
23. Peterson AM, Nau DP, Cramer JA, Benner JS, Gwadry-Sridhar F, Nichol M. A checklist for medication compliance and persistence studies using retrospective databases. Value Health. 2007;10(1):3-12. Available at: http://www. ispor.org/workpaper/research_practices/Peterson_Scientific_Report.pdf. Accessed November 11, 2012.

24. Cramer JA, Roy A, Burrell A, et al. Medication compliance and persistence: terminology and definitions. Value Health. 2008;11(1):44-47. Available at: http://www.ispor.org/workpaper/research_practices/Cramer.pdf. Accessed November 11, 2012.

25. Quan H, Sundararajan V, Halfon P, et al. Coding algorithms for defining comorbidities in ICD-9-CM and ICD-10 administrative data. Med Care 2005;43(11):1130-39.

26. Rubin DT, Siegel CA, Kane SV, et al. The impact of ulcerative colitis from patients' and physicians' perspectives: results from the UC: NORMAL survey. Inflamm Bowel Dis. 2009;15(4):581-88. Available at: http://onlinelibrary. wiley.com/doi/10.1002/ibd.20793/pdf. Accessed November 11, 2012.

27. D'Incà R, Bertomoro P, Mazzocco K, Vettorato MG, Rumiati R, Sturniolo GC. Risk factors for nonadherence to medication in inflammatory bowel disease patients. Aliment Pharmacol Ther. 2008;27(2):166-72. Available at: http://onlinelibrary.wiley.com/doi/10.1111/j.1365-2036.2007.03555.x/pdf. Accessed November 11, 2012.

28. Jackson CA, Clatworthy J, Robinson A, Horne R. Factors associated with nonadherence to oral medication for inflammatory bowel disease: a systematic review. Am J Gastroenterol. 2010;105(3):525-39.

29. Cervený P, Bortlík M, Kubena A, Vlcek J, Lakatos PL, Lukás M. Nonadherence in inflammatory bowel disease: results of factor analysis. Inflamm Bowel Dis. 2007;13(10):1244-49. Available at: http://onlinelibrary. wiley.com/doi/10.1002/ibd.20189/pdf. Accessed November 11, 2012.

30. Nahon S, Lahmek P, Saas C, et al. Socioeconomic and psychological factors associated with nonadherence to treatment in inflammatory bowel disease patients: results of the ISSEO survey. Inflamm Bowel Dis. 2011;17(6):1270-76

31. Ediger JP, Walker JR, Graff L, et al. Predictors of medication adherence in inflammatory bowel disease. Am J Gastroenterol. 2007;102(7):1417-26.

32. Moshkovska T, Stone MA, Clatworthy J, et al. An investigation of medication adherence to 5-aminosalicylic acid therapy in patients with ulcerative colitis, using self-report and urinary drug excretion measurements. Aliment Pharmacol Ther. 2009;30(11-12):1118-27. Available at: http://onlinelibrary.wiley.com/ doi/10.1111/j.1365-2036.2009.04152.x/pdf. Accessed November 11, 2012. 33. McWilliams JM. Health consequences of uninsurance among adults in the United States: recent evidence and implications. Milbank $Q$. 2009;87(2):443-94

34. Sabik LM. The effect of community uninsurance rates on access to health care. Health Serv Res. 2012;47(3 Pt 1):897-918.

35. Steiner JF, Prochazka AV. The assessment of refill compliance using pharmacy records: methods, validity, and applications. J Clin Epidemiol. 1997:50(1):105-16.

36. Choo PW, Rand CS, Inui TS, et al. Validation of patient reports, automated pharmacy records, and pill counts with electronic monitoring of adherence to antihypertensive therapy. Med Care. 1999;37(9):846-57.

37. Nichol MB, Knight TK, Priest JL, Wu J, Cantrell CR. Nonadherence to clinical practice guidelines and medications for multiple chronic conditions in a California Medicaid population. J Am Pharm Assoc (2003). 2010;50(4):496-507.

38. Briesacher BA, Andrade SE, Fouayzi H, Chan KA. Comparison of drug adherence rates among patients with seven different medical conditions. Pharmacotherapy. 2008;28(4):437-43. Available at: http://www.ncbi.nlm.nih gov/pmc/articles/PMC2737273/. Accessed November 11, 2012.

39. Yeaw J, Benner JS, Walt JG, Sian S, Smith DB. Comparing adherence and persistence across 6 chronic medication classes. J Manag Care Pharm. 2009;15(9):728-40 